\title{
Kinetics of the appearance of cereal alkylresorcinols in pig plasma
}

\author{
Anna-Maria Linko ${ }^{1 *}$, Alastair B. Ross ${ }^{2,3}$, Afaf Kamal-Eldin ${ }^{2}$, Anja Serena ${ }^{4}$, Anna Kirstin Bjørnbak Kjær ${ }^{4}$, \\ Henry Jørgensen ${ }^{4}$, José L. Peñalvo ${ }^{1}$, Herman Adlercreutz ${ }^{1}$, Per Åman ${ }^{2}$ and Knud Erik Bach Knudsen ${ }^{3,4}$ \\ ${ }^{1}$ Institute for Preventive Medicine, Nutrition and Cancer, Folkhälsan Research Centre and Department of Clinical Chemistry, \\ PO Box 63, University of Helsinki, FIN-00014, Helsinki, Finland \\ ${ }^{2}$ Department of Food Science, Swedish University of Agricultural Science (SLU), Box 7051, S-750 07 Uppsala, Sweden \\ ${ }^{3}$ Nestlé Research Centre, Lausanne 26, CH-1000, Switzerland \\ ${ }^{4}$ Department of Animal Health, Welfare and Nutrition, Danish Institute of Agricultural Sciences, PO Box 50, Research Centre \\ Foulum, DK-8830 Tjele, Denmark
}

(Received 6 May 2005 - Revised 12 August 2005 - Accepted 5 October 2005)

\begin{abstract}
Alkylresorcinols (AR) are phenolic lipids found in high amounts in wholegrain wheat and rye. They may be important as bioactive components and/or biomarkers of wholegrain wheat and rye intake. AR absorption was studied with pigs during a habitual diet and after a single meal of ARrich diet. In study 1, four pigs were fed wholegrain rye (RD) and white wheat bread (WD) for 1 week in a cross-over design. Arterial and venous AR concentrations were determined over $540 \mathrm{~min}$ after feeding on days 5 and 7 . In study 2, four pigs were fed a synthetic, starch-based diet for $5 \mathrm{~d}$, and arterial and venous AR concentrations were determined over $960 \mathrm{~min}$ after feeding a single meal of RD. In study 1, plasma AR concentrations after consuming RD peaked at $120 \mathrm{~min}$, remained elevated between 120 and $420 \mathrm{~min}$, and were re-elevated on refeeding at 480 min. In study 2 , AR appeared in the plasma after $60 \mathrm{~min}$, peaked at 180-240 min, and remained elevated after $960 \mathrm{~min}$. The apparent elimination half-life was $3.93 \mathrm{~h}$, and the maximum plasma concentration was 666 (SEM 35) nmol/l. Arterial and venous plasma AR concentrations were similar, suggesting that AR are absorbed via the lymphatic system. AR concentrations in pig plasma increase rapidly after a meal containing AR, and persist in plasma for at least $5 \mathrm{~d}$, indicating that AR may be a useful biomarker of wholegrain wheat and rye intake.
\end{abstract}

Alkylresorcinols: Biomarkers: Wholegrain cereals: Rye

Epidemiological studies have linked wholegrain cereal consumption to many health benefits, including a reduction of the risk of CVD, diabetes, obesity, and some cancers (Levi et al. 2000; Truswell, 2002; Hallmans et al. 2003; Jensen et al. 2004). This has been recognised by the Food and Drug Administration and other national food and nutrition agencies, who allow certain health claims to be made for wholegrain cereal products (Kantor et al. 2001).

However, these health claims are only based on epidemiological studies, and no long-term intervention studies have been done to establish a direct link between wholegrain cereal consumption and the proposed health benefits, in part due to the lack of a suitable biomarker of wholegrain cereal intake (Branca et al. 2001). Such a biomarker is needed due to the combined factors of the difficulty that consumers have in identifying wholegrain foods (Slavin et al. 2001), and weaknesses in methods used for dietary recall (Bingham et al. 2003). A biomarker of wholegrain intake could be used to check for compliance in intervention studies, accuracy in epidemiological studies, and can indicate dietary intake where no dietary record is available (for example, samples from a blood bank). Having more reliable information about wholegrain intake would increase the strength of the current health claims for whole grains, and possibly lead to new associations for wholegrain cereal intake and a decreased risk of other diseases. Alkylresorcinols (1,3-dihydroxy-5alkylbenzene derivatives; AR), present in wholegrain wheat and rye, are candidate biomarkers of the intake of these cereals (Ross et al. 2004d; Linko et al. 2005).

AR are long-chain phenolic lipids found in some higher plants, fungi and bacteria. In cereals they are mainly present as five different homologues with odd-numbered saturated hydrocarbon side chains between seventeen and twenty-five carbons long. AR are present in high amounts in the bran of wheat and rye, but not in refined (white) wheat flour (for example, endosperm), germ, nor in significant amounts in other foods (Ross et al. 2003c), and thus can be considered to be specific for wholegrain wheat and rye (Chen et al. 2004). The nutritional effects of AR in the diet are essentially unknown, but their intake $(20-40 \mathrm{mg}$ /individual per $\mathrm{d}$ in the Nordic countries) is high relative to other phenolic compounds (Ross et al. 2005). AR are absorbed by pigs (Ross et al.

Abbreviations: AR, alkylresorcinols; AUC, area under the curve; BW, body weight; RD, rye diet; SSD, synthetic starch-based diet; WBSD, wheat-barley-soyabean diet; WD, wheat diet.

* Corresponding author: Dr Anna-Maria Linko, fax +358 9191 25452, email Anna.Linko@helsinki.fi 
2003b) and man (Ross et al. 2003a) (60-80 and $60 \%$ absorption respectively), and can be measured intact in human plasma (Linko et al. 2002) and as metabolites in human urine (Ross et al. 2004b). In vitro and in vivo studies have shown that AR have many potential bioactivities, including the ability to integrate into and modify phospholipid membranes, cleave DNA, increase $\gamma$-tocopherol levels in rats, and inhibit enzymes and cell carcinogenesis (Kozubek \& Tyman, 1999; Ross et al. 2004c,d; Linko \& Adlercreutz, 2005). Wholegrain rye intake and plasma alkylresorcinol concentrations have been correlated (Linko et al. 2005), providing strong evidence that they can be biomarkers of wholegrain wheat and rye intake.

Before AR can be properly investigated as bioactive compounds in vivo or as a possible biomarker for wholegrain wheat and rye intake, more must be understood about their intake, and the kinetics of their absorption, metabolism and excretion. In these experiments, we used a catheterised pig model to study the kinetics of AR appearance and clearance in plasma.

\section{Materials and methods}

\section{Breads and diets}

The diets used in the present study have been described previously (Bach Knudsen et al. 2003). The diets were made of wheat soft and crisp bread (WD) or rye soft and crisp bread (RD). Wheat and rye soft breads were produced at Nordmills (Nordmills, Cerealia AB, Malm $\varnothing$, Sweden) and wheat and rye crisp bread were produced at Wasa Bread (Wasa Bread AB, Filipstad, Sweden). The rye crisp bread contained wholegrain rye flour, rye bran (Wasa T2), fat and salt as the main ingredients and the corresponding wheat crisp bread contained white wheat flour, purified wheat fibre (essential cellulose, Vitacel WF 600; Rettenmair and Söhne, Ellwagen-Holzmühle, Germany), sugar, salt and dry malt. The soft rye bread contained white wheat flour, rye bran (B3-fin; Nordmills, Cerealia AB, Uppsala, Sweden), baker's yeast, fat, salt and sugars (sucrose) and the corresponding soft wheat bread contained white wheat flour, Vitacel, baker's yeast, fat, salt and sugar. Immediately after production, the soft bread was frozen at $-20^{\circ} \mathrm{C}$ until consumption, while crisp bread was stored dry. The diets prepared from soft and crisp bread were balanced with vitamins and minerals and provided about 19, 15 and 66\% energy from fat, protein and carbohydrates, respectively (see Table 1 for diet ingredients and composition). A semi-synthetic diet (SSD) was made from wheat starch $(707.8 \mathrm{~g} / \mathrm{kg})$, cellulose $(80 \cdot 0 \mathrm{~g} / \mathrm{kg})$, casein $(182 \cdot 2 \mathrm{~g} / \mathrm{kg})$ and vitamins and minerals $(28 \mathrm{~g} / \mathrm{kg})$.

\section{Experimental design and pigs}

The whole study comprised two series of experiments; in study 1 the appearance of AR was measured in the plasma of pigs fed either RD or WD and in study 2 the kinetics of the appearance of AR in pigs after feeding a single meal of the AR-rich diet (RD) was determined.

Study 1. The study was carried out using a cross-over design with four pigs fed the two experimental diets for 1 week each and blood sampled on day 5 and day 7 from each pig $(n 4)$. Four male castrated pigs from the Danish Institute of Agricultural Sciences' Swine herd, Foulum, Denmark,
Table 1. Ingredients and chemical composition of the experimental diets

\begin{tabular}{|c|c|c|}
\hline Diet... & Wheat diet & Rye diet \\
\hline \multicolumn{3}{|l|}{ Ingredients (g/kg DM) } \\
\hline Wheat crisp bread & 602 & - \\
\hline Wheat soft bread & 370 & - \\
\hline Rye crisp bread & - & 593 \\
\hline Rye soft bread & - & 379 \\
\hline Vitamins and minerals* & 28 & 28 \\
\hline \multicolumn{3}{|l|}{ Chemical composition ( $\mathrm{g} / \mathrm{kg}$ DM) } \\
\hline Ash & 33 & 56 \\
\hline Protein $(\mathrm{N} \times 6.25)$ & 119 & 127 \\
\hline Fat & 68 & 73 \\
\hline Total carbohydrates & 773 & 699 \\
\hline Sugars & 24 & 40 \\
\hline Fructans & 4 & 18 \\
\hline Starch & 529 & 455 \\
\hline Total NSP & 220 & 203 \\
\hline Total soluble NSP & 23 & 55 \\
\hline Cellulose & 131 & 20 \\
\hline$\beta$-Glucan & 12 & 19 \\
\hline Total soluble $\beta$-glucan & 1 & 7 \\
\hline Arabinoxylans & 53 & 127 \\
\hline Total soluble arabinoxylans & 13 & 36 \\
\hline Klason lignin & 10 & 32 \\
\hline Dietary fibre (NSP + lignin) & 230 & 237 \\
\hline Alkylresorcinols ( $\mu \mathrm{g} / \mathrm{g} \mathrm{DM})$ & 0 & 1158 \\
\hline \multicolumn{3}{|l|}{ Homologuest } \\
\hline $17: 0$ & 0 & 262 \\
\hline $19: 0$ & 0 & 372 \\
\hline $21: 0$ & 0 & 284 \\
\hline $23: 0$ & 0 & 134 \\
\hline $25: 0$ & 0 & 106 \\
\hline
\end{tabular}

*Vitamins and minerals (mg/kg diet): $\mathrm{Ca}_{2}\left(\mathrm{PO}_{4}\right)_{3}, 14000 ; \mathrm{NaCl}, 4000$ $\mathrm{CaCO}_{3}, 8000 ; \mathrm{FeSO}_{4} .5 \mathrm{H}_{2} \mathrm{O}, 50 ; \mathrm{ZnO}, 80 ; \mathrm{MnO}, 27 ; \mathrm{CuSO}_{4} .5 \mathrm{H}_{2} \mathrm{O}$ 20; KI, 0.2; $\mathrm{Na}_{2} \mathrm{SeO}_{3}, 0.3$; retinyl acetate, 1.1; cholecalciferol, 0.01; all-rac $\alpha$-tocopherol, 60; menadione, 2; riboflavin, 4; pantothenic acid, 11; cobalamin, 0.02; niacin, 22; biotin, 0.06.

† Molecular weights of alkylresorcinols (g/mol): 17: 0, 348; 19: 0, 376; 21: 0,$404 ; 23: 0,432 ; 25: 0,460$.

For details of diets and procedures, see this page.

with an initial average body weight of 44.6 (SEM 2.4) kg were used in the study. Each pig was surgically fitted with two catheters, one in the portal vein (internal diameter $0.050 \mathrm{~cm}$; external diameter $0.090 \mathrm{~cm}$; wall $0.02 \mathrm{~cm}$; Buch \& Holm, Denmark) and the second in the mesenteric artery (internal diameter $0.040 \mathrm{~cm}$; external diameter $0.070 \mathrm{~cm}$; wall $0.015 \mathrm{~cm}$; Buch \& Holm, Denmark), and with an ultrasonic blood-flow probe (14 mm; Transonic System, Ithaca, NY, USA) around the portal vein. A flowmeter (Transonic ${ }^{\circledR}$ T201D flowmeter with P-option; Transonic System) was used for measuring the flow rate. The pigs were given Streptocillin for up to $4 \mathrm{~d}$ after surgery. Up to 1 week before surgery the pigs were fed a habitual diet made from wheat, barley and soyabean meal (WBSD). The last week before surgery and the first $10 \mathrm{~d}$ after surgery (recovery period), the pigs were fed a diet based on wholegrain rye ( $873 \mathrm{~g}$ wholegrain rye $/ \mathrm{kg}$ ) fortified with casein, vitamins and minerals. After $10 \mathrm{~d}$ of post-surgery recovery, the pigs were gradually introduced to the two experimental diets and fed 1250 (SEM 15) g DM/d (2.4\% DM of body weight (BW)) of WD or 1250 (SEM 24) g DM/d (2.5\% $\mathrm{DM}$ of $\mathrm{BW}$ ) of RD. The bread was cut into pieces, mixed $1: 2 \cdot 5(\mathrm{w} / \mathrm{w})$ with water and fed in equal amounts three times daily, at 07.00, 15.00 and 22.00 hours. The portal and arterial blood spot samples were collected twice weekly on days 5 
and 7 at $-30,0,30$ and $60 \mathrm{~min}$, then at $60 \mathrm{~min}$ intervals up to $480 \mathrm{~min}$ after the morning feeding and then again at $540 \mathrm{~min}$. The blood was collected in two heparinised plastic tubes $(9 \mathrm{ml}$ and $4 \mathrm{ml}$ ) and one EDTA heparinised plastic tube $(2 \mathrm{ml})$ and centrifuged ( $3000 \mathrm{rpm}$ for $10 \mathrm{~min}$ at $8^{\circ} \mathrm{C}$ ) to separate the erythrocytes from plasma. The plasma was kept frozen at $-20^{\circ} \mathrm{C}$ until analysis.

Study 2. Four pigs (three the same as in study 1, average weight $48 \cdot 2$ (SEM 6.3) kg, were fed SSD three times daily for $4 \mathrm{~d}$ and the morning feeding on day 5 . The pigs were then deprived of food for $24 \mathrm{~h}$ and then on day 6 fed one meal (492 g DM; $1 \%$ DM of BW) of RD, after which blood spot samples were taken at $-30,0,30$ and $60 \mathrm{~min}$, and then at 60 min intervals to $960 \mathrm{~min}$ after the morning feeding, after which the animals were fed RD. The experiment was repeated for all the pigs the following week $(n 4)$.

All animal experiments complied with the guidelines of the Danish Ministry of Justice with regard to animal experimentation and care of animals under study.

\section{Analytical methods}

Analysis of macronutrients in the diets is described elsewhere (Bach Knudsen et al. 2003). AR in the diets were analysed using a gas chromatographic method for cereal grains modified for bread (Ross et al. 2003c), and GC-MS where necessary (Ross et al. 2001). AR in plasma samples were analysed by GC-MS (Linko et al. 2002). The interseries CV for plasma AR values was always under $15 \%$.

\section{Calculations and statistical analysis}

The pharmacokinetic parameters calculated were maximum plasma concentration $\left(\mathrm{C}_{\max }\right)$, time of peak concentration observed $\left(\mathrm{t}_{\max }\right)$, area under the plasma concentration time curve from 0 to 8 or $15 \mathrm{~h}\left(\mathrm{AUC}_{0-8 \mathrm{~h}} / \mathrm{AUC}_{0-15 \mathrm{~h}}\right)$ corrected for baseline $(0 \mathrm{~h})$, the elimination half-life and absorption half-life. The parameters were calculated with PK Solutions 2.0 Noncompartmental Pharmacokinetics Data Analysis program (Summit Research Services, Montrose, CO, USA).

Minitab version 11 (State College, PA, USA) and SPSS 11.0.1 for Windows (SPSS Inc., Chicago, IL, USA) were used for all statistical calculations. Differences were determined using
Student's $t$ test and the general linear model with repeated measures, and were considered significant at $P<0 \cdot 05$. Values are reported as means with their standard errors.

\section{Results}

No AR were detected in diet WD, while diet RD contained $1158 \mu \mathrm{g} \mathrm{AR/g} \mathrm{DM.} \mathrm{The} \mathrm{basal} \mathrm{diet} \mathrm{(WBSD),} \mathrm{which} \mathrm{had} \mathrm{been}$ consumed by the pigs since weaning, contained low concentrations of $\mathrm{AR}(54 \mu \mathrm{g} \mathrm{AR/g} \mathrm{DM})$ and is probably, along with the wholegrain-based rye diet $(655 \mu \mathrm{g} \mathrm{AR/g} \mathrm{DM})$ fed during the recovery period after surgery, responsible for the low concentrations of AR observed in pigs fed the AR-free diets (see p. 284). The AR homologue composition in the $\mathrm{RD}$ and WBSD is given in Table 2.

Concentrations of AR in the mesenteric artery and portal vein for both studies were similar $\left(r^{2} 0.96\right.$ (SEM 0.02)) (Figs. 1 and 2), and did not differ in homologue composition either. The total plasma AR concentration and plasma AR homologue composition described here are the average of the values for the mesenteric artery and portal vein at the given time point.

\section{Study 1: appearance of alkylresorcinols in plasma during a habitual alkylresorcinol-free or alkylresorcinol-rich diet}

Although AR could not be detected in WD, the basal concentration of AR in the plasma of pigs fed WD was 35 (SEM 4.6) $\mathrm{nmol} / \mathrm{l}$ at $30 \mathrm{~min}$ before feeding. After feeding, there was a peak AR concentration of 74 (SEM 7.5) nmol/l at $180 \mathrm{~min}$ (range $64-112 \mathrm{nmol} / \mathrm{l}, 120-480 \mathrm{~min}$; different from baseline (0 min) $(P<0 \cdot 01)$ (Fig. 1).

The pigs fed RD ate about $3733 \mu \mathrm{mol} \mathrm{AR} / \mathrm{d}$, corresponding to $1244 \mu \mathrm{mol} \mathrm{AR/meal} \mathrm{(three} \mathrm{meals/d).} \mathrm{The} \mathrm{concentration} \mathrm{of}$ $\mathrm{AR}$ in the plasma of pigs fed a habitual RD was 260 (SEM 77) $\mathrm{nmol} / \mathrm{l}$ at $30 \mathrm{~min}$ before feeding, increasing to 662 (SEM 92) $\mathrm{nmol} / \mathrm{l}$ at $240 \mathrm{~min}$ (range $538-1406 \mathrm{nmol} / \mathrm{l}$, 180-360 min) (Fig. 1). At the end of the $480 \mathrm{~min}$ trial, plasma AR concentrations remained significantly elevated above baseline concentrations (370 (SEM 52) nmol/l; $P<0 \cdot 01)$. Pigs were fed again with RD at $480 \mathrm{~min}$, and $1 \mathrm{~h}$ later, plasma AR concentrations had risen to 631 (SEM 140) nmol/l. The relative AR homologue composition in the

Table 2. Percentage homologue distribution of alkylresorcinols (AR) in the rye diet, wheat diet and wheat-barleysoyabean (WBS, basal) diet, and the average homologue distribution in plasma after feeding either the rye diet (191 plasma samples) or wheat diet during study 1 (186 plasma samples)*

(Mean values with their standard errors)

\begin{tabular}{|c|c|c|c|c|c|c|c|}
\hline \multirow[b]{2}{*}{ AR homologues } & \multirow[b]{2}{*}{ Rye diet (\%) } & \multicolumn{2}{|c|}{$\begin{array}{c}\text { Rye diet } \\
\text { plasma }(\%)^{\star}\end{array}$} & \multirow[b]{2}{*}{ Wheat diet (\%) } & \multirow[b]{2}{*}{ WBS diet (\%) } & \multicolumn{2}{|c|}{$\begin{array}{c}\text { Wheat diet } \\
\text { plasma }(\%)^{*} \dagger\end{array}$} \\
\hline & & Mean & SEM & & & Mean & SEM \\
\hline $17: 0$ & 25 & 22 & 0.4 & nd & 12 & 13 & 0.3 \\
\hline $19: 0$ & 33 & 44 & 0.2 & nd & 29 & 37 & 0.4 \\
\hline $21: 0$ & 24 & 21 & 0.2 & nd & 41 & 30 & 0.5 \\
\hline $23: 0$ & 10 & 8 & 0.1 & nd & 10 & 13 & 0.2 \\
\hline $25: 0$ & 8 & 5 & 0.2 & nd & 8 & 8 & 0.2 \\
\hline
\end{tabular}

nd, not detected.

${ }^{*}$ The homologue composition of rye diet plasma and wheat diet plasma was significantly different $(P<0.009)$.

† AR concentrations in the wheat diet plasma are probably from the basal (WBS) diet.

For details of diets and procedures, see p. 283. 


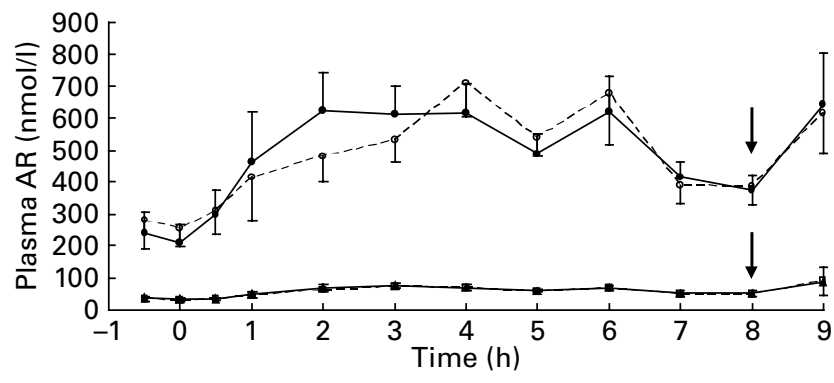

Fig. 1. Average portal vein $(-\bigcirc-,-\square-)$ and mesenteric artery $(-\bullet-,-\mathbf{\Delta}-)$ plasma alkylresorcinol (AR) concentrations in pigs $(n 4)$ during habitual feeding of an AR-rich rye diet $\left(-\bullet-,-\mathrm{O}_{-}\right)$and an AR-free wheat diet $(-\boldsymbol{\Lambda}-,-$ $\square-)$. Pigs were fed at $0 \mathrm{~h}$ and again at $8 \mathrm{~h}(\downarrow)$. Values are means, with their standard errors represented by vertical bars. For details of diets and procedures, see p. 283.

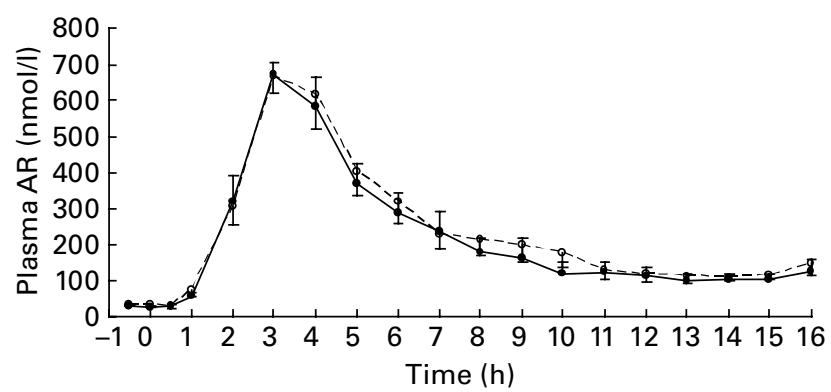

Fig. 2. Appearance of alkylresorcinols $(A R)$ in the portal vein (-O-) and mesenteric artery $(-\bullet-)$ plasma of pigs $(n 4)$ after the intake of a single meal of an AR-rich rye diet $(0 \mathrm{~h})$. Values are means, with their standard errors represented by vertical bars. For details of diets and procedures, see p. 283.

plasma of pigs fed WD was significantly different $(P<0 \cdot 001)$ compared with when the pigs were fed RD (Table 2), indicating that the dietary source of AR is reflected in the plasma AR homologue composition.

The incremental AUC for 480 min $(8 \mathrm{~h})$ after the pigs were fed the WD was $223($ SEM 20) $\mathrm{nmol} / \mathrm{l} \times \mathrm{h}$ (range $151-$ $306 \mathrm{nmol} / \mathrm{l} \times \mathrm{h})($ Table 3$)$. There was a non-significant trend that the AUC for the second set of samples taken while the pigs were fed WD were slightly lower than the first, indicating that the baseline concentration of AR in the plasma of pigs eating an AR-free diet decreases between the two sampling periods $(2 \mathrm{~d})$. The incremental AUC for pigs fed RD was approximately ten times higher than when feeding the
WD diet $(2219 \quad(\mathrm{SEM} \quad 308) \quad \mathrm{nmol} / \mathrm{l} \times \mathrm{h} ; \quad$ range $1291-$ $4015 \mathrm{nmol} / \mathrm{l} \times \mathrm{h})$. Here, there was a non-significant trend that plasma AR concentrations increased for the second set of samples taken. As there was no clear peak or clearance of plasma AR, it was not possible to calculate the half-life of plasma AR during either habitual diet.

Study 2: appearance of alkylresorcinols in plasma after a single feeding of an alkylresorcinol-rich diet

Pigs ate a single meal of RD containing $1471 \mu \mathrm{mol}$ AR. The baseline AR concentration in plasma after a $5 \mathrm{~d}$ AR-free diet was 30 (SEM 3.7) nmol/l, similar to that of the baseline concentrations with WD in study 1 . AR started appearing in the mesenteric artery and the portal vein at $60 \mathrm{~min}$ and peaked at 180-240 min with 666 (SEM 35) nmol/l (range $500-989 \mathrm{nmol} / \mathrm{l} ; 180-240 \mathrm{~min}$ ) (Fig. 2). At the end of the 960 min time period, the average AR concentration was 136 (SEM 34) nmol/l, nearly five times the baseline plasma AR concentration $(P<0.05)$.

The homologue composition of plasma was fairly consistent in both arterial and venous samples throughout the study, and was similar to that for rye diet plasma in study 1 (Table 2). There was a significant difference in plasma homologue composition for the main homologues, C17 : 0, C19:0 and $\mathrm{C} 21$ : 0 , between $-30,0$ and $30 \mathrm{~min}$ and the rest of the time points $(P=0.001-0 \cdot 005)$, but not for $\mathrm{C} 23: 0$ and $\mathrm{C} 25: 0$ (data not shown).

The incremental $\mathrm{AUC}_{(0-15 \mathrm{~h})}$ for the appearance of $\mathrm{AR}$ in plasma over $15 \mathrm{~h}$ was 3190 (SEM 279) $\mathrm{nmol} / \mathrm{l} \times \mathrm{h}$ (range $2035-4083 \mathrm{nmol} / \mathrm{l} \times \mathrm{h})$ corrected for baseline $(0 \mathrm{~min})$ concentrations (Table 3). The AUC value was always larger for the second duplicate experiment $(74.2-1793 \mathrm{nmol} / \mathrm{l} \times \mathrm{h})$. There was no significant difference in $\mathrm{AUC}_{(0-15 \mathrm{~h})}$ between venous and arterial samples. The absorption half-life and apparent elimination half-life of $\mathrm{AR}$, determined from the mean concentration of all pigs, were $1.20 \mathrm{~h}$ and $3.93 \mathrm{~h}$ respectively.

\section{Discussion}

To better understand the kinetics of the appearance of AR in plasma, and to further study whether plasma AR concentrations may be a suitable biomarker of wholegrain wheat and rye intake, we determined the appearance of AR in pig plasma during habitual intake of AR and after a single meal of AR. No significant differences between AR concentrations

Table 3. Pharmacokinetic parameters of the appearance of alkylresorcinols (AR) in pig plasma*

(Mean values with their standard errors or range)

\begin{tabular}{|c|c|c|c|c|c|c|c|c|c|}
\hline & \multicolumn{2}{|c|}{$\mathrm{C}_{\max }(\mathrm{nmol} / \mathrm{l})$} & \multicolumn{2}{|c|}{$t_{\max }(h)$} & \multicolumn{2}{|c|}{$\begin{array}{c}\operatorname{AUC}_{(0-t)} \\
(\mathrm{nmol} / \mathrm{I} \times \mathrm{h})\end{array}$} & \multicolumn{2}{|c|}{$\begin{array}{c}\text { Baseline } \\
(\mathrm{nmol} / \mathrm{l})\end{array}$} & \multirow[b]{2}{*}{ AR introduced ( $\mu \mathrm{mol} /$ feeding) } \\
\hline & Mean & SEM & Mean & Range & Mean & SEM & Mean & SEM & \\
\hline Study 1 wheat diet (habitual intake) & 74 & $7 \cdot 5$ & 3 & $2-8$ & 223 & 20 & 35 & $4 \cdot 6$ & - \\
\hline Study 1 rye diet (habitual intake) & 662 & 92 & 4 & $3-6$ & 2219 & 308 & 260 & 77 & 1244 \\
\hline Study 2 (single feeding after fasting) & 666 & 35 & 3 & $3-4$ & 3190 & 279 & 30 & 3.7 & 1471 \\
\hline
\end{tabular}

$\mathrm{C}_{\max }$, maximum plasma concentration; $\mathrm{t}_{\max }$, time of maximum plasma concentration; $\mathrm{AUC}_{(0-\mathrm{t})}$, area under the plasma concentration curve from $0-8 \mathrm{~h}(\mathrm{study} 1)$ or $0-15 \mathrm{~h}$ (study 2).

For details of diets and procedures, see p. 283. 
in the mesenteric artery and the portal vein were detected, indicating that $\mathrm{AR}$ are not taken up directly to the portal vein as is the case with glucose, amino acids, and SCFA (Rérat et al. 1984; Rérat, 1985; van der Meulen et al. 1987; Bach Knudsen et al. 2000), but probably via the lymphatic system. It is also clear from the appearance times of AR in plasma that they are taken up more slowly compared with, for example, glucose where peak concentrations in the portal vein will be found 20-30 min post-feeding (Bach Knudsen et al. 2000). This agrees with earlier ileostomy studies on AR disappearance from the small intestine (Ross et al. $2003 a, b$ ), which indirectly suggest that $\mathrm{AR}$ are taken up via the lymphatic system as for other lipid-soluble compounds.

Because there was no difference between arterial and venous AR concentrations, it was not possible to calculate actual absorption of AR over time - only the response of AR concentrations in plasma to the intake of a rye diet. The mean apparent elimination half-life of AR was similar to that of tocotrienols $(2 \cdot 3-4.4 \mathrm{~h})$ (Schwedhelm et al. 2003; Yap et al. 2004), as was the time of peak concentration observed (3.3-4.4 h for tocotrienols) (Yap et al. 2004). AR have a similar lipophilicity to tocopherols and tocotrienols (Ross et al. 2004d), and are metabolised in a similar manner (Ross et al. 2004b), so may be expected to have a similar mode of uptake and transport within the body.

The amount of AR appearing in plasma as determined by the AUC was low relative to the amount fed, but determination of the pharmacokinetics of absorption and bioavailability of lipid-soluble compounds from plasma concentrations alone is not advisable (Traber, 2000) and it is not yet clear how good a reflection plasma AR concentrations are of total AR absorption.

In study 1 , habitual consumption of $\mathrm{RD}$ gave a plasma AR curve with a broad peak spanning $4 \mathrm{~h}$, and 'baseline' AR concentrations over three times higher than when the pigs were fed WD $(P<0 \cdot 001)$. Human subjects eating a diet rich in wholegrain rye had fasting plasma AR concentrations almost ten times greater than when they consumed a diet with almost no AR (Linko et al. 2005). Therefore, as would be expected, feeding a diet rich in AR leads to an increase in baseline plasma AR concentrations compared with a diet not containing any AR.

The baseline concentrations of AR (about $30 \mathrm{nmol} / \mathrm{l}$ ) observed when the pigs were fed an AR-free diet (WD or SSD) in both studies was not expected. However, it may be in part due to storage of AR in body tissues and blood cells (Ross et al. 2004c; Linko \& Adlercreutz, 2005). The pigs had been fed WBSD, which contained small amounts of $\mathrm{AR}$, since weaning, and a wholegrain-based rye diet during the recovery period. Unmetabolised AR may be mobilised from certain tissues or blood cells into the plasma. It is also possible that there were very low levels of $A R$ in the WD as indicated by plasma AR concentrations approximately doubling after feeding the WD, in spite of the fact that analysis by GC-MS did not indicate that any AR were present.

In study 2, AR appeared in the plasma $1 \mathrm{~h}$ after feeding a single meal of $\mathrm{RD}$, with a peak $3-4 \mathrm{~h}$ after feeding. This peak is sharper than that of the peak during the habitual diet, but also somewhat higher, likely to be due to the $24 \mathrm{~h}$ fasting period, which will cause the ingested nutrients to pass faster to the small intestine than when consuming the habitual diet. Thus, a more even gastric emptying rate may be responsible for the broader peak of plasma AR concentrations during a habitual diet than after a single meal. The concentration of AR, $16 \mathrm{~h}$ after feeding, remained about four to five times higher than before feeding the RD (Fig. 2). Since the decrease in plasma AR concentration could not be adapted to an ordinary decay curve it is possible that AR undergo enterohepatic circulation, as is the case with the mammalian lignan enterolactone (Bach Knudsen et al. 2003). These conditions could maintain the concentration of AR in the blood after a meal. However, the enterohepatic circulation of newly administered $\alpha$-tocopherol in rats is low (0.98-1.78\% of administered dose) (Lee-Kim et al. 1988), indicating that if AR have a similar mode of absorption, then other mechanisms might be involved. This aspect should be investigated when analytical methods to analyse $\mathrm{AR}$ in the lymph and bile become available (Ross et al. 2004a).

The AR homologue composition of plasma appeared to reflect the diet consumed (Table 1), which is interesting as this may be a way of determining whether specifically wheat or rye were consumed from plasma AR homologue concentrations. The ratio of homologues $\mathrm{C} 17: 0$ and $\mathrm{C} 21: 0$ have been used to differentiate between wheat and rye in cereal products (Chen et al. 2004) and differs in human plasma after consumption of either wholegrain wheat or rye bread (Linko et al. 2005).

In a previous study feeding a single dose of radiolabelled $\mathrm{AR}$ to rats the peak of radioactivity (intact and metabolised AR) in the blood was at about $12 \mathrm{~h}$ (Ross et al. 2003b). In study 2, the peak of intact AR was at 3-4h. The difference between the two studies may be a result of species differences, or matrix effects of the source of AR in the diets. It also may be due to the metabolism of AR (Ross et al. 2004b), and that $3-4 \mathrm{~h}$ represents the peak of intact AR, but there may be a later peak of AR metabolites. Methods to analyse AR metabolites in plasma are needed before this can be confirmed.

The pigs here were fed a much higher amount of AR than is normally consumed by even extreme habitual consumers of wholegrain wheat and rye (about $1450 \mathrm{mg} /$ pig per d compared with about $160 \mathrm{mg} /$ person per d) (Ross et al. 2005). Human subjects consuming a habitual diet rich in rye $(200 \mathrm{mg} \mathrm{AR} / \mathrm{d})$ have fasting plasma AR concentrations of 352 (SEM 24.7) nmol/l (Linko et al. 2005), within the range measured in the pigs fasted after a rye meal during habitual feeding of RD. The plasma of human subjects following a 1-week AR-free diet also contained low amounts of AR ( $32 \mathrm{nmol} / \mathrm{l})$ (Linko \& Adlercreutz, 2005), similar to those concentrations in pigs after a $5 \mathrm{~d}$ AR-free diet, indicating that fasting plasma AR concentrations are similar between pigs and man in spite of large differences in intake and dietary factors likely to influence absorption (for example, fat). If AR intake is corrected for dietary fibre to account for the more varied diet of man, there is little difference in AR intake; $4.9 \mathrm{mg} \mathrm{AR} / \mathrm{g}$ fibre for pigs in the present study, and $5.5 \mathrm{mg} \mathrm{AR} / \mathrm{g}$ fibre for human subjects (Linko et al. 2005), the diets resulting in similar plasma AR concentrations. It is also possible that there is a biologically determined upper limit for the amount of AR in plasma, given that feeding increasing doses of the similarly lipophilic $\alpha$-tocopheryl acetate to human subjects does not lead to corresponding increases in plasma $\alpha$-tocopherol 
(Traber, 2000), and that AR are able to disrupt erythrocyte membranes at micromolar concentrations (Kozubek \& Tyman, 1999).

Along with other studies (Linko et al. 2002, 2005; Ross et al. 2003a), results from the present study suggest that measurement of AR concentrations in plasma might be a good biomarker of intake of diets rich in wholegrain wheat or rye. That AR are present in the plasma of pigs previously fed RD, even after a $5 \mathrm{~d}$ AR-free diet, suggests that they may be useful short- to long-term markers for wholegrain wheat and rye intake. Our knowledge of the fate of AR upon absorption is limited, and it appears that measurement of plasma AR does not account for all absorbed AR. Further studies on the kinetics of AR absorption and their fate thereafter are required, as well as studies to determine if plasma AR status is a good reflection of AR absorption and short- and/or long-term wholegrain wheat and rye intake.

\section{Acknowledgements}

We thank Winnie Østergaard Thomsen for excellent technical assistance. The present study was supported by the Nordic Industrial Fund; the Danish Agricultural and Veterinary Research Council; Cerealia AB, Sweden; Wasabröd AB, Sweden; Vaasan \& Vaasan, Finland; Fazer Oululainen, Finland. A.-M. L. was supported by the Sigrid Jusélius Foundation, Helsinki, Finland and Finska Läkaresällskapet, Helsinki, Finland. The authors had no conflicts of interest regarding this manuscript and no funding was received from a source benefiting from these findings.

\section{References}

Bach Knudsen KE, Canibe N \& Jørgensen H (2000) Quantification of the absorption of nutrients deriving from carbohydrate assimilation: model experiment with catheterised pigs fed on wheat and oat based rolls. Br J Nutr 84, 449-458.

Bach Knudsen KE, Serena A, Bjørnbak Kjaer AK, Tetens I, Heinonen S-M, Nurmi T \& Adlercreutz H (2003) Rye bread in the diet of pigs enhances the formation of enterolactone and increases its levels in plasma, urine and feces. J Nutr 133, 1368-1375.

Bingham SA, Luben R, Welch A, Wareham N, Khaw KT \& Day N (2003) Are imprecise methods obscuring a relation between fat and breast cancer?" Lancet 362, 212-214.

Branca F, Hanley AB, Pool-Zobel B \& Verhagen H (2001) Biomarkers in disease and health. Br J Nutr 85, S55-S92.

Chen Y, Ross AB, Åman P \& Kamal-Eldin A (2004) Alkylresorcinols as markers of whole-grain wheat and rye in cereal products. J Agric Food Chem 52, 8242-8246.

Hallmans G, Zhang J-X, Lundin E, Stattin P, Johansson A, Johansson I, Hultén K, Winkvist A, Lenner P, Åman P \& Adlercreutz H (2003) Rye, lignans and human health. Proc Nutr Soc 62, 193-199.

Jensen MK, Koh-Banerjee P, Hu FB, Franz M, Sampson L, Grønbæk M \& Rimm EB (2004) Intakes of whole grains, bran, and germ and the risk of coronary heart disease in men. Am J Clin Nutr 80, $1492-1499$.

Kantor LS, Variyam JN, Allshouse JE, Putnam JJ \& Lin B-H (2001) Choose a variety of grains daily, especially whole grains: a challenge for consumers. J Nutr 131, 473S-486S.

Kozubek A \& Tyman JHP (1999) Resorcinolic lipids, the natural nonisoprenoid phenolic amphiphiles and their biological activity. Chem Rev 99, 1-25.
Lee-Kim YC, Meydani M, Kassarjian Z, Blumberg JB \& Russell RM (1988) Enterohepatic circulation of newly administered $\alpha$-tocopherol in the rat. Int J Vitam Nutr Res 58, 284-291.

Levi F, Pasche C, Lucchini F, Chatenoud L, Jacobs DRJ \& La Vecchia C (2000) Refined and whole-grain cereals and the risk of oral, oesophageal and laryngeal cancer. Eur J Clin Nutr 54, 487-489.

Linko A-M \& Adlercreutz H (2005) Whole grain rye and wheat alkylresorcinols are incorporated into human erythrocyte membranes. Br J Nutr 93, 11-13.

Linko A-M, Juntunen KS, Mykkänen HM \& Adlercreutz H (2005) Whole-grain rye bread consumption by women correlates with plasma alkylresorcinols and increases their concentration compared with low-fiber wheat bread. J Nutr 135, 580-583.

Linko A-M, Parikka K, Wähälä K \& Adlercreutz H (2002) Gas chromatographic - mass spectrometric method for the determination of alkylresorcinols in human plasma. Anal Biochem 308, $307-313$.

Rérat AA (1985) Intestinal absorption of end products from digestion of carbohydrates and proteins in the pig. Archiv Tierernährung $\mathbf{3 5}$, $461-480$.

Rérat AA, Vaissade P \& Vaugelade P (1984) Absorption kinetics of some carbohydrates in conscious pigs. 2. Quantitative aspects. $B r J$ Nutr 51, 517-529.

Ross AB, Aman P, Andersson R \& Kamal-Eldin A (2004a) Chromatographic analysis of alkylresorcinols and their metabolites. J Chromatogr 1054A, 157-164.

Ross AB, Åman P \& Kamal-Eldin A (2004b) Identification of cereal alkylresorcinol metabolites in human urine-potential biomarkers of wholegrain wheat and rye intake. J Chromatogr 809B, 125-130.

Ross AB, Becker W, Chen Y, Kamal-Eldin A \& Åman P (2005) Intake of alkylresorcinols from wheat and rye in the United Kingdom and Sweden. Br J Nutr 94, 496-499.

Ross AB, Chen Y, Frank J, Swanson JE, Parker RS, Kozubek A, Lundh T, Vessby B, Åman P \& Kamal-Eldin A (2004c) Cereal alkylresorcinols elevate g-tocopherol levels in rats and inhibit g-tocopherol metabolism in vitro. J Nutr 134, 506-510.

Ross AB, Kamal-Eldin A \& Åman P (2004d) Dietary alkylresorcinols: absorption, bioactivities, and possible use as biomarkers of whole-grain wheat- and rye-rich foods. Nutr Rev 62, 81-95.

Ross AB, Kamal-Eldin A, Jung C, Shepherd MJ \& Åman P (2001) Gas chromatographic analysis of alkylresorcinols in rye (Secale cereale L) grains. J Sci Food Agric 81, 1405-1411.

Ross AB, Kamal-Eldin A, Lundin EA, Zhang JX, Hallmans G \& Åman P (2003a) Cereal alkylresorcinols are absorbed by humans. J Nutr 133, 2222-2224.

Ross AB, Shepherd MJ, Bach Knudsen KE, Glits $\varnothing$ LV, Bowey E, Phillips J, Rowland I, Guo Z-X, Massy DJR, Åman P \& KamalEldin A (2003b) Absorption of dietary alkylresorcinols in ilealcannulated pigs and rats. Br J Nutr 90, 787-794.

Ross AB, Shepherd MJ, Schüpphaus M, Sinclair V, Alfaro B, KamalEldin A \& Åman P (2003c) Alkylresorcinols in cereals and cereal products. J Agric Food Chem 51, 4111-4118.

Schwedhelm E, Maas R, Troost R \& Böger RH (2003) Clinical pharmacokinetics of antioxidants and their importance on systemic oxidative stress. Clin Pharmacokinet 42, 437-459.

Slavin JL, Jacobs D, Marquart L \& Wiemer K (2001) The role of whole grains in disease prevention. J Am Diet Assoc 101, 780-785.

Traber MG (2000) The bioavailability bugaboo. Am J Clin Nutr $\mathbf{7 1}$, $1029-1030$.

Truswell AS (2002) Cereal grains and coronary heart disease. Eur J Clin Nutr 56, 1-14.

van der Meulen J, Bakker JG, Smits B \& de Visser H (1987) Effects of source of starch on net portal flux of glucose, lactate, volatile fatty acids and amino acids in the pig. Br J Nutr 78, 533-544.

Yap SP, Yuen KH \& Wong JW (2004) Pharmacokinetics and bioavailability of a-, g- and d-tocotrienols under different food status. Pharmaceutical Press 53, 67-71. 